\title{
Pilar Gonzalbo Aizpuru (2013), Educación, familia y vida cotidiana en el México virreinal, México, El Colegio de México,
}

\author{
Fernando Mata Rosas \\ Instituto Cultural Helénico \\ fmatarosas@icloud.com
}

Es ampliamente reconocida la trayectoria de la doctora Pilar Gonzalbo Aizpuru, investigadora de El Colegio de México, en temas de Historia de la Vida Cotidiana. Sus estudios relacionados con la Historia Cultural han abierto líneas de investigación que permiten enriquecer, diversificar e inclusive contrariar lo que sabemos sobre la familia, las tradiciones, los sentimientos y la educación de la sociedad novohispana, por mencionar sólo algunos temas. Así mismo, cuenta con un amplio catálogo de libros, artículos, colaboraciones, ponencias, etc., que son evidencia de la innumerable cantidad de preguntas que la autora se ha formulado para darle una estructura organizada a los aspectos en los cuales ha enfocado su interés historiográfico. La obra que nos ocupa en estas líneas es una especie de compilación, un "corte de caja", que sin aspirar a convertirse en una antología personal, busca hacer una pausa para lograr un rescate de lo que ella misma ha escrito desde sus primeras publicaciones. Según su propia justificación, el libro tiene la intención de recopilar algunos de los textos breves publicados a lo largo de 30 años. La autora expone cómo durante su carrera le han surgido preguntas relacionadas con la sociedad virreinal, para lo cual se ha concentrado en la tarea de investigar de qué manera se ha dado ese proceso de cambio en dicha sociedad, a partir de una diversidad de cuestionamientos que ha intentado responder. Por supuesto, reconoce que no siempre ha tenido las fuentes suficientes para contestar a todos los interrogantes formulados, pero ciertamente su esfuerzo se ha centrado en encontrar un mayor conocimiento de aquellas sociedades. Para ello, ha escrito y publicado cientos de artículos, algunos actualmente difíciles de localizar. Educación, familia y vida cotidiana en el México virreinal intenta integrar los más relevantes, ya sea por su contenido o por su difícil 
accesibilidad, pero buscando encontrar coherencia en relación con diferentes aspectos de la vida cotidiana en la Nueva España.

Esta compilación se presenta en dos partes, la primera se trata de un libro de 167 páginas, organizado en una introducción y seis artículos que aparecieron originalmente en otras fuentes explícitamente identificadas. Mientras que la segunda parte utiliza la versatilidad de los archivos electrónicos, generando un disco compacto (CD) que reúne 60 artículos, organizados en tres tópicos: Sobre educación y lectura; Sobre sociedad, familia y matrimonio, y Sobre cultura material y vida cotidiana. Cada artículo incluye los datos de la publicación original, lo cual deja ver que sus trabajos han aparecido en una diversidad de libros y revistas de universidades, colegios, institutos de investigación y sociedades académicas, tanto nacionales como internacionales que incluyen países como Venezuela, Perú, Colombia, Puerto Rico, Nicaragua, Brasil, España, Francia, Alemania, los Estados Unidos y por supuesto, México.

Si bien en este libro se compilan publicaciones alrededor del tema general Historia de la vida cotidiana en el México virreinal, de ninguna manera pretende convertirse en una antología de la obra de la investigadora, lo cual requeriría una edición mucho más amplia y generosa si consideramos su prolífico catálogo. Parte de su producción se enlista en un apéndice con los datos de los libros de autoría personal y coordinación de volúmenes colectivos, alrededor de los temas de Familia, Educación y Vida Cotidiana quedando excluidos los libros completos, las ponencias o artículos dedicados a temas diferentes a la vida cotidiana en la etapa novohispana.

En cuanto a su organización, la autora nos propone una clasificación en las tres categorías mencionadas, aunque reconoce lo difícil que es marcar una separación tajante entre los temas. Las continuas interacciones entre educación, familia, sociedad y vida cotidiana, elementos presentes en su temática general, cubren un amplio rango de aspectos de la vida cotidiana en la Nueva España, incluyendo títulos sugestivos como: "La lectura de investigación en la Nueva España"; "Mitos y realidades de la educación colonial"; "La oculta modernidad jesuítica"; "De fruto e fraude. Nuevas concepciones de moralidad para los indígenas del siglo XVI"; "La cruz, el arado y el libro; La vida familiar novohispana en los concilios provinciales"; "Ajuar doméstico y vida familiar"; "Entre la calle y el claustro ¿Cuál es la dicha mayor?"; "La intimidad divulgada. La comunicación escrita en la vida privada en la Nueva España". Esto nos puede dar una idea de la diversidad de aspectos tratados en los artículos y de la interrelación que poseen.

El recorrido que se puede hacer a través de la lectura de tantos temas, generará sin duda un vasto acopio de información sobre la época, pero sobre todo, será fuente de preguntas inagotables. Así, el lector no sólo podrá plantearse preguntas y encontrar respuestas, sino que esto además lo conducirá a ampliar el territorio de lo cotidiano, llevándolo a una diversidad de conceptos que se relacionan entre sí, que conforman una intrincada red, la cual 
mientras más se estudie, seguramente se volverá más compleja y será la génesis de nuevos cuestionamientos.

En especial, resulta de sumo interés la postura de Gonzalbo sobre la educación, ya que la asume como una integración de las esferas escolar, familiar y social, en las que tienen cabida las tradiciones, las relaciones interpersonales, las creencias, los valores, lo político, además de las acciones específicas de enseñanza, escolarizadas o no. Esto abre la perspectiva respecto a reducir la educación a las escuelas, a las aulas, textos, maestros, estrategias de instrucción u objetivos de aprendizaje, que si bien son altamente relevantes en el proceso educativo, siempre están en articulación con otras dimensiones que afectan también en lo formativo de la persona, la familia y la sociedad. Todo esto, en su conjunto, a partir de sus relaciones, coincidencias y diferencias, constituye lo que podríamos conceptualizar como educación.

Por otra parte, la autora declara que "[...] tras varios años de estudio, pude identificar errores repetidos que, por su misma reiteración, habían terminado por ser aceptados como verdades indiscutibles". Esta declaración encierra uno de los objetivos de sus investigaciones: dar validez al conocimiento. Entre los propósitos paralelos que la investigadora ha mantenido a lo largo de su trayectoria académica está la lucha contra los mitos y estereotipos de la época. Lo primero que se tendría que considerar es la inadecuación de generalizar e inferir como permanentes las costumbres, la organización, las relaciones en la vida cotidiana de la Nueva España en el transcurrir de tres siglos. Como toda sociedad, se puede apreciar una transformación con el paso del tiempo, una evolución paulatina y permanente de la educación, la familia y la sociedad, que en conjunción con los cambios en el derecho, la política y la economía -que por cierto, poco tratamiento explícito tienen en los contenidos abordados-, van dando cuenta de la dinámica de las sociedades novohispanas al paso de los siglos.

Poco se parecen los conceptos, las formas y los estilos de la sociedad novohispana del siglo XVI con lo que imperaba en el siglo XVIII o en la primera década del XIX. De esta manera, los artículos en esta obra no se refieren a la totalidad de los temas en el transcurso de 300 años. Algunos se ubican en las condiciones inmediatas a la consumación de la Conquista y la ocupación de los territorios de los indios por parte de los españoles; otros, abordan las características específicas de la vida de los habitantes de la Nueva España en los albores del siglo XIX, pasando, por supuesto, a través de artículos que se ubican en los siglos XVII y XVIII. De este modo, la compilación no pretende dar una visión longitudinal del desarrollo de la educación, la familia y la sociedad a lo largo de todo el periodo virreinal; se trata en realidad de cortes transversales que ubican aspectos particulares de dichas temáticas en periodos determinados. Serán el lector y el investigador quienes se encarguen de retomar estos resultados para darles la orientación temporal y espacial de acuerdo con los intereses personales. 
Una constante que se encuentra en los artículos de Gonzalbo se refiere a las preguntas precisas que pueden guiar sus investigaciones y se convierten en el objetivo a alcanzar. Muchos de los artículos forman parte de acercamientos a las respuestas, en ocasiones haciendo sondeos a manera de muestra de las fuentes disponibles, pero en general forman parte de proyectos más extensos y especializados que le permiten llegar a un mejor conocimiento de los símbolos culturales y de sus posibles significados.

La autora justifica algunos de sus artículos, mediante preguntas precisas que dan cuenta de una diversidad de aspectos a estudiar para construir cada vez un mayor entendimiento de la vida en aquellos años, tales como "¿Se independizaban a diferentes edades los hijos de estas familias (españoles, mestizos, indios, castas)? o ¿En qué hogares se aceptaba con más facilidad a niños jóvenes entenados o adoptados?”.

Quizás un punto medular en la propuesta de Gonzalbo, tiene que ver con la educación dirigida a los naturales por parte de las autoridades hispanas, ya que más allá del mito de buscar la mayor cobertura y calidad, la pregunta pertinente que nos formula es: ¿Acaso era deseable y de beneficio para la Corona el que los indios se integraran a la sociedad criolla y accedieran a las mismas oportunidades? A partir de esto, cada lector podría plantear sus propias preguntas al revisar los diversos artículos incluidos. Por mi parte, enfocándome en el interés personal por los procesos educativos dirigidos a los indios en tal periodo, se me ocurre plantear las siguientes preguntas: ¿Los españoles buscaron en algún momento de esos 300 años una integración con los indios? ¿La educación -o la falta de ella- pretendía ser para los españoles una manera de tener control sobre los millones de indios que habitaban el extenso territorio de la Nueva España? ¿De qué manera fueron cambiando los propósitos educacionales dirigidos a los indios en los tres siglos de dominio? ¿Por qué los españoles finalmente buscaron a través de la educación la castellanización y alfabetización de los indios? ¿En qué se basaba la decisión para determinar quiénes eran candidatos a la educación y a quiénes era mejor mantenerlos alejados de la educación y cultura españolas? ¿Qué temores enfrentaron la Corona y los españoles en general, al darse cuenta del potencial de aprendizaje, aptitud y talentos que los indios, o al menos algunos de ellos, podrían demostrar? ¿Qué cambios tuvo la educación conforme se diluía la línea que separaba al indio del mestizo, al mestizo del criollo, al criollo del español? ¿Qué criterios determinaron que la fundación de escuelas dirigidas a los indios se estableciera en ciertos lugares $y$ no en otros? Y muchas otras que surgen conforme se analizan los contenidos de los tópicos que conforman esta obra.

Ciertamente se podrían plantear muchos más interrogantes, incluyendo las categorías de sociedad, familia y vida cotidiana, algunas de las cuales podrían estar resueltas en sus artículos y seguramente muchas otras quedarían pendientes de respuesta. La autora asume esta cuestión con toda claridad cuando expresa: "En mi búsqueda de explicaciones las preguntas se multiplicaban a medida que descubría los puntos débiles de los prototipos con- 
vencionales". A la par, podríamos decir que plantearse nuevas preguntas ha sido la guía de su trabajo durante más de tres décadas; la idea de analizar el conocimiento que se tiene sobre el virreinato, relacionarlo con nuevas fuentes e interpretaciones, que ayude a derribar mitos arraigados en el devenir histórico.

De tal forma, en sus artículos es común que presente las fuentes de su trabajo de investigación y la necesidad de que sus argumentos se articulen metodológicamente sobre bases y fuentes precisas, y así sus hallazgos puedan contribuir a enriquecer, complementar o sustituir el conocimiento que tenemos de esos temas y a la vez, puedan ser el eslabón que lleve a nuevas investigaciones y conocimiento; "Como sucede con los avances de los estudios sobre cualquier tema, a nuevas respuestas acompañan nuevas preguntas y a las relaciones cuantitativas suceden indagaciones cualitativas", según asienta Gonzalbo.

La autora nos ofrece una amplia perspectiva de la vida familiar en el virreinato al romper con el estereotipo de la conformación familiar que dictaban la Iglesia o las representaciones de los cuadros de castas. De ese modo, nos entrega, en forma alternativa, un amplio rango de familias, acordes con una sociedad compleja, que poco tienen que ver con las idealizadas imágenes católicas de la Sagrada Familia — que tanto ha sido difundida-.

Archivos parroquiales, censos de población, inventarios de bibliotecas y librerías, cartas personales, listas de bienes de difuntos, listas de gastos y de precios, denuncias..., son sólo algunas de las fuentes de información que utiliza la investigadora para tratar el estudio de la vida cotidiana. Pero principalmente se centra en detalles y elementos que parecieran secundarios: "el testamento -nos recuerda- no sólo muestra un aspecto legal, sino que revela información que permite reconstruir las formas de vida cotidiana en aquella época". Gonzalbo resalta aquello que pareciera pasar inadvertido, que no tiene carácter protagónico o que solamente forma parte del contexto material, de "la escenografía", es decir, los muebles, la comida, la vajilla, la vestimenta, los utensilios, las fabricaciones locales o las importaciones chinas. Mediante ello, nos habla de las personas, de los usuarios, de cómo se utilizaban tales objetos, de las costumbres, de las diferencias sociales y del poder adquisitivo, de las valoraciones y hasta de las devociones. Su análisis conduce a que los reflejos de aquellas fuentes conviertan lo secundario en prioritario, en protagonista.

Con tal perspectiva, no escatima en seguirse planteando preguntas para nuevas investigaciones. Como ella misma refiere: "Nuevamente las preguntas se acumulan" y son el enfoque que permitirá interpretar las diversas fuentes a las que va teniendo acceso.

La autora identifica la diversidad de cuestiones que la han ocupado durante muchos años, pero también reconoce que no siempre ha podido encontrar suficientes evidencias para fundamentar todas sus tesis, propuestas e intuiciones. De cualquier modo, ofrece generosamente el fruto de su trabajo y mediante una modestia cuestionable expresa su deseo de que este legado "quizá" pueda servirle a jóvenes historiadores interesados en la temática, cuando 
es evidente que esta compilación de 66 artículos resultará de gran interés a estudiantes e investigadores afines a esas líneas de conocimiento.

"Sé que estoy dejando sin respuesta muchas de las preguntas que alguna vez me formulé", aclara Gonzalbo, pero eso nos puede marcar la pauta para asumir que esta obra no es una antología final, ni el anuncio de su retiro; se trata simplemente de una compilación de muchos artículos dispersos, los cuales concentra en un volumen doble (libro y CD) que deja abierta la perspectiva de seguir avanzando en la construcción de las ideas que tenemos sobre cómo era la vida cotidiana, allá en el México virreinal. 